\title{
THE EFFECT OF BED PERMEABILITY ON OSCILLATORY BOUNDARY LAYER FLOW
}

\author{
Kathryn Sparrow ${ }^{1}$, Dubravka Pokrajac ${ }^{1}$ and Dominic A. van der $\mathrm{A}^{1}$
}

\begin{abstract}
This experimental study consists of a series of full-scale experiments involving oscillatory boundary layer flow over an impermeable bed and a permeable bed. Velocity measurements have been obtained through particle image velocimetry, and the effect of bed permeability on the velocity profile, phase lead, boundary layer thickness, bed shear stress (as estimated by fitting the log law), and finally the resulting friction factor is presented. For our rough turbulent flows over a permeable bed it has been found that the friction factor is increased by up to $36 \%$ and that the friction factor also demonstrates a dependence on Reynolds number.
\end{abstract}

Keywords: oscillatory flow, boundary layer, permeable bed.

\section{INTRODUCTION}

Fundamental oscillatory boundary layer flow has been extensively researched in the past but experimental studies, such as Jonsson and Carlsen (1976), Sleath (1987), Jensen et al. (1989), and, more recently, van der A et al. (2011), have mainly investigated oscillatory boundary layer flow over impermeable beds. These experiments were conducted over a single layer of material that had been glued to a solid base, therefore rendering the bed impermeable. There are very few detailed studies that have been conducted over a permeable bed, despite that in the field, beds often consist of gravel or coarse sand and therefore the possible effect of bed permeability should be taken into account. The practical applications of this study such as coastal erosion and sediment transport on steep gravel beaches, or wave attenuation over permeable breakwaters, are becoming increasingly significant as our coasts become areas of conservation.

Conley and Inman (1994) investigated ventilated oscillatory boundary layers over a permeable bed where they forced oscillating suction or injection of varying rates through the permeable bed. They concluded that the velocity profile was sensitive to the vertical flow through the bed and found that the stream-wise velocity profile was either pulled closer to the bed or pushed further away from the bed when the flow was subjected to suction or injection respectively. The change in the velocity profile leads to an increase (with suction) or decrease (with injection) in the bed shear stress accordingly. This indicates that the horizontal flow is sensitive to the vertical exchange of fluid that could occur due to the natural mixing of the boundary layer flow and the porous flow within the bed.

There are a larger number of studies in other fields of environmental fluid mechanics that have investigated the effect of a permeable bed on the boundary layer. These fields, such as open channel flows or atmospheric flows, have concluded that for permeable beds the velocity profiles, turbulence and shear stress are significantly different to the impermeable bed. These studies have been conducted generally for steady flow conditions with well-developed boundary layers but similar or analogous physical processes may also occur in unsteady oscillatory flow conditions. A few studies are mentioned below.

Zagni and Smith (1976) were the first to investigate open channel flow over permeable beds by conducting flume tests over beds that consisted of lead shot or steel spheres of varying permeability. The flow conditions tested were in the rough turbulent flow regime with $R e \sim$ $O\left(10^{5}\right)$. Zagni and Smith found that for the permeable bed the velocity profiles are distinctly different when compared to an impermeable bed. For flow over the permeable bed the zero velocity is suppressed below the surface of the bed, resulting in a finite slip velocity and a significantly different velocity profile. This has also been supported by direct numerical simulations of Breugem et al. (2006), who conducted a series of simulations of uni-directional flow between two plates, one of which was permeable. Their simulations showed that as the porosity of the permeable plate increased so did the alteration in the velocity profile. The result of a different velocity profile consequently leads to a difference in bed shear stress and therefore friction factor. Zagni and Smith (1976) concluded that for flows over a permeable bed the overall

${ }^{1}$ School of Engineering, University of Aberdeen, Fraser Noble Building, King's College, Aberdeen, AB24 3UE. Scotland. 
friction loss is greater than that for flow over an equivalent impermeable bed with the resulting friction factor increasing by up to $16 \%$ in their case. The studies of Kong and Schetz (1982), Zippe and Graf (1983), and Breugem et al. (2006) also showed a significant increase in friction factors of up to $30-40 \%$ depending on the porosity. This increase in friction factor has been attributed to the vertical exchange of momentum which causes an additional dissipation of energy across the interface between the boundary layer flow and the permeable bed.

Another conclusion that arose from the studies of Zagni and Smith (1976) and Zippe and Graf (1983) is that both studies found that not only is the friction factor higher for the permeable bed case but also that the friction factor increases with Reynolds number. This effect has been further investigated for open channel flow over a gravel bed by Manes et al. (2011), who also concluded that the friction factor has a dependence on Reynolds number. For rough bed oscillatory flow at high Reynolds number, where the flow is classed as being within the rough turbulent flow regime, the friction factor tends to a constant for a given relative bed roughness as shown, for example, by Jonsson (1966) and Kamphuis (1975). However, widely used friction factor formulae such as Swart (1974) and Nielsen (1992) assume that the friction factor has no dependence on Reynolds number so may need to be adapted if they are applied to flows over permeable beds. Alternatively, a separate formula for the friction factor over permeable beds, one that is dependent on Reynolds number and bed porosity may need to be derived.

The experiments in this study have therefore been specifically designed to answer, for oscillatory flow conditions, the following research questions:

- Is there a difference in friction factor for an impermeable bed and a permeable bed?

- Does the friction factor for flows over permeable beds depend on Reynolds number?

\section{EXPERIMENTAL SET UP}

The experiments undertaken for this study were conducted in the Aberdeen Oscillatory Flow Tunnel (AOFT) shown in Fig. 1. The tunnel is of U-tube construction, is $16 \mathrm{~m}$ in length and has a glass-sided test section that is $7 \mathrm{~m}$ long, $0.75 \mathrm{~m}$ high and $0.3 \mathrm{~m}$ wide with large reservoirs at both ends to accommodate the displaced flow. A piston, controlled by an electro-hydraulic valve, is located at one end of the tunnel to drive the oscillatory motion.

A total of six experiments were conducted, these consisted of three flow conditions over two test beds. The material used for the test beds was a $9 \mathrm{~mm}$ coarse gravel with a grain distribution of $8 \mathrm{~mm}$ to $10 \mathrm{~mm}$. The impermeable bed was constructed from a single layer of gravel which is glued with varnish to a $30 \mathrm{~mm}$ thick marine plywood base, this has been constructed in a similar manner to the fixed beds of Sleath (1987), Jensen et al. (1989) and van der A et al. (2011). As indicated in Fig. 1 the plywood base was mounted to a stainless steel frame in order to raise it to the desired height within the test section. The permeable bed was constructed from a $250 \mathrm{~mm}$ deep layer of the same $9 \mathrm{~mm}$ gravel, of which the top $40 \mathrm{~mm}$ has been fixed using a weak cementgravel mixture with a ratio of water:cement:gravel of 1:2:67. The effect on the permeability using this method was tested in hydraulic conductivity tests and was found to be negligible. This method has also been successfully used by Steenhauer (2010) to conduct swash experiments over a rigid permeable bed.

The flow conditions were selected so that they are within the rough turbulent regime and in a similar data range to the conditions of Sleath (1987) and van der A et al. (2011). The flow conditions were defined such that the flow amplitude and therefore the relative bed roughness remain constant throughout the set of experiments, but to allow the free-stream velocity and flow Reynolds number to vary with the period of the flow. This is to investigate how, and if, the effect of bed permeability is also related to the flow period and Reynolds number, as well as directly comparing the impermeable and permeable bed cases.

The flow conditions are detailed in Table 1. Flow periods are 5, 6 and 7 seconds. The orbital amplitude, $a$, has been calculated from the measured free-stream velocity time series using $a=$ $\sqrt{2} u_{0 \mathrm{rms}} / \omega$, where $u_{0 \mathrm{rms}}$ is the root mean square of the free-stream velocity and $\omega=2 \pi / T$, where $T$ is the flow period. Reynolds number is given by $R e=u_{0 \max } a / v$, where $u_{0 \max }$ is the maximum free-stream velocity and $v$ is the kinematic viscosity of water, equal to $1.12 \times 10^{-6} \mathrm{~m}^{2} / \mathrm{s}$ for the 
present study. The relative bed roughness is calculated as $a / k_{\mathrm{s}}$ where $k_{\mathrm{s}}$ is found from the logarithmic fit to the measured velocity profiles.
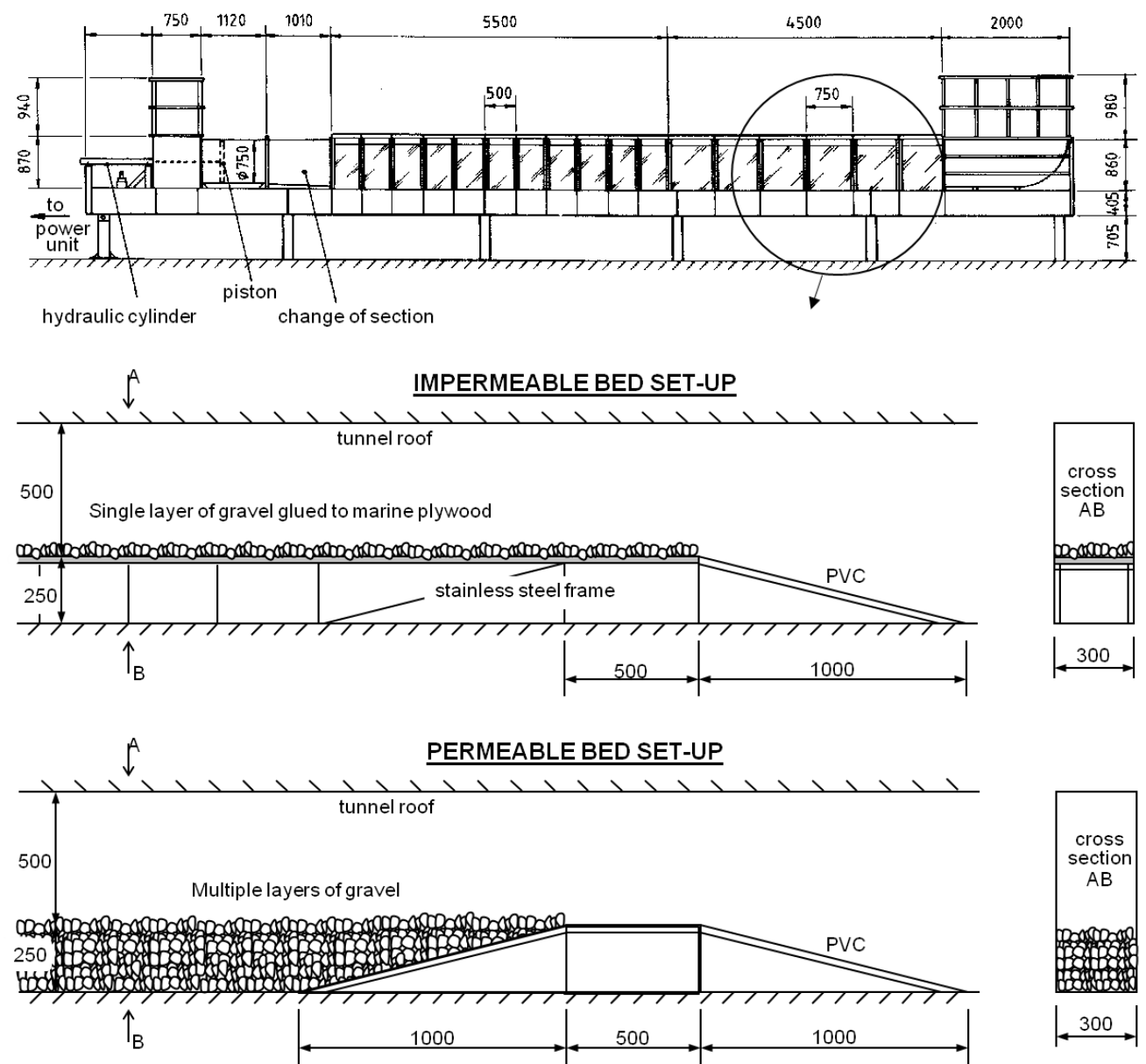

Figure 1: Aberdeen Oscillatory Flow Tunnel (adapted from van der A (2010)

\begin{tabular}{|l|l|l|l|l|l|l|}
\hline \multicolumn{7}{|l|}{ Table 2.1 Flow conditions } \\
\hline Flow ID & $\mathrm{a}(\mathrm{m})$ & $\mathrm{k}_{\mathrm{s}}$ & $\mathrm{a} / \mathrm{k}_{\mathrm{s}}$ & $\mathrm{T}(\mathrm{s})$ & $\mathrm{U}_{0}(\mathrm{~m} / \mathrm{s})$ & $\operatorname{Re}\left(\times 10^{5}\right)$ \\
\hline FC1 & 0.78 & 0.014 & 56 & 5 & 0.94 & 6.5 \\
FC2 & 0.78 & 0.014 & 56 & 6 & 0.80 & 5.6 \\
FC3 & 0.78 & 0.014 & 56 & 7 & 0.70 & 4.9 \\
\hline
\end{tabular}

\section{Velocity measurements}

The main method used for measuring the oscillatory flow velocity was Particle Image Velocimetry (PIV). PIV is an optical non-invasive measurement technique that was used to obtain the horizontal $(u)$ and vertical $(w)$ component of a 2D flow field in the middle of the test section across the tunnel centerline. Here the PIV setup consists of a New Wave Solo III doublepulsed Nd:YAG laser, a Dantec Dynamics 80N53 timer box, Flowsense 2M 1600 x 1200 pixel 
CCD camera, all controlled by Dantec Dynamics Studio software. The water was seeded using $20 \mu \mathrm{m}$ titania coated hollow glass microspheres that have a relative density of 1 . PIV essentially captures image pairs of the seeding and through cross-correlation tracks its displacement between the two images providing a representation of the flow. For this study pairs of images were obtained at a rate of $15 \mathrm{~Hz}$, with the images in a pair being taken $1000 \mu \mathrm{s}$ apart. Two measurements areas were established, measurement area 1 (MA1) is $120 \mathrm{~mm}$ high and $160 \mathrm{~mm}$ wide, this is sufficiently high to capture the entire boundary layer and the free-stream velocity. Measurement area 2 (MA2) is only 30mm high and 40mm wide, this set-up allows for a higher resolution so more detailed measurements near the bed can be obtained. These measurement areas are split into smaller interrogation areas for processing the velocities. The interrogation areas are $1.6 \mathrm{~mm}(\mathrm{~h})$ by $3.2 \mathrm{~mm}(\mathrm{w})$ for MA1 and for MA2 the interrogation area is $1 \mathrm{~mm}(\mathrm{~h})$ by $1 \mathrm{~mm}(\mathrm{w})$. The resulting velocities have then been phase-averaged over 50 flow cycles, and spatially-averaged across the PIV measurement window.

\section{RESULTS}

\section{Velocity Profiles}

Fig. 2 illustrates a comparison of the velocity profiles over the impermeable bed and the permeable bed at $30^{\circ}$ phase intervals for condition $\mathrm{FC} 1$, where the free-stream velocity is $0.94 \mathrm{~m} / \mathrm{s}$, the period is $5 \mathrm{~s}$ and the orbital amplitude is $0.78 \mathrm{~m}$. The velocity profiles in Fig. 2 display the key features of oscillatory boundary layer flow, such as the velocity overshoot, a feature where the velocity in the boundary layer is greater than the maximum free-stream velocity and it can also be seen that the expected phase lead exists in the flow, whereby the near bed velocities are ahead of the free-stream velocity; this will be shown in more detail in the next section. However, the most prominent feature in Fig. 2 is that the velocity profiles over the impermeable bed and the permeable bed are distinctly different, particularly near the bed. Throughout the whole cycle the velocity near the bed is lower for the permeable bed compared to the impermeable case. This suggests that the near-bed velocities are retarded by the presence of the permeable bed. This was also noted in the uni-directional study of Breugem et al. (2006), who attributed the reduced velocity to the vertical exchange of fluid between the boundary layer and the porous flow which created a higher resistance to the stream-wise flow. This could also apply to this study with the permeable bed allowing for an exchange of flow, which cannot occur for the impermeable bed case. Alternatively, the difference in the velocity profiles can be attributed to a potential difference in phase lead between the two cases in the near- bed region, this is reviewed in the next section.

Fig. 2 also illustrates that the presence of the permeable bed seems to affect not just the flow closest to the bed but the entire lower $10 \mathrm{~mm}$ of the boundary layer, creating a significantly different velocity profile in this region. Whilst the velocity profile for the impermeable bed tends to zero as the elevation from the bed decreases, the permeable bed profile displays a distinctly different feature. For the velocity profile over the permeable bed an inflection in the velocity profile exists, this is a common feature of atmospheric boundary layer flows over vegetation canopy, which are usually described using a mixing layer analogy (Finnigan, 2000; Raupach et al. 1996).

In addition to these points Fig. 2 further shows that the difference in the velocity profiles near the bed is more pronounced during the accelerating stages of the flow, so when $t / T$ is between $0-0.25$ and again when $t / T$ is between $0.5-0.75$. During the decelerating stages, when $t / T$ is $0.25-0.5$ and $0.75-1$, the two cases exhibit a similar velocity profile. The reason behind this has not yet been investigated, but this could be linked to the turbulence developing near the bed during the accelerating flow, which enhances the mixing of the flow between the boundary layer and the porous flow, thus hindering the stream-wise velocities. As turbulence is known to dissipate away from the bed in the decelerating flow, the mixing at the interface could reduce, hence leading to the noticeable difference in the accelerating and the decelerating velocity profiles. 

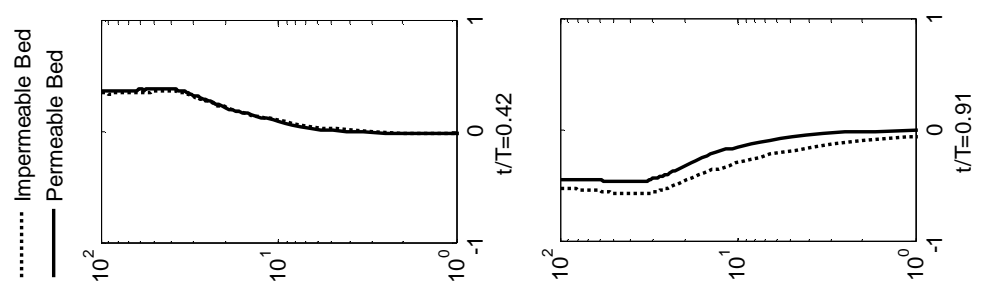

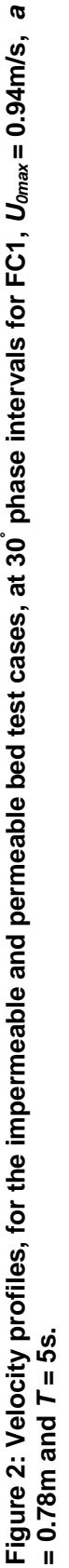
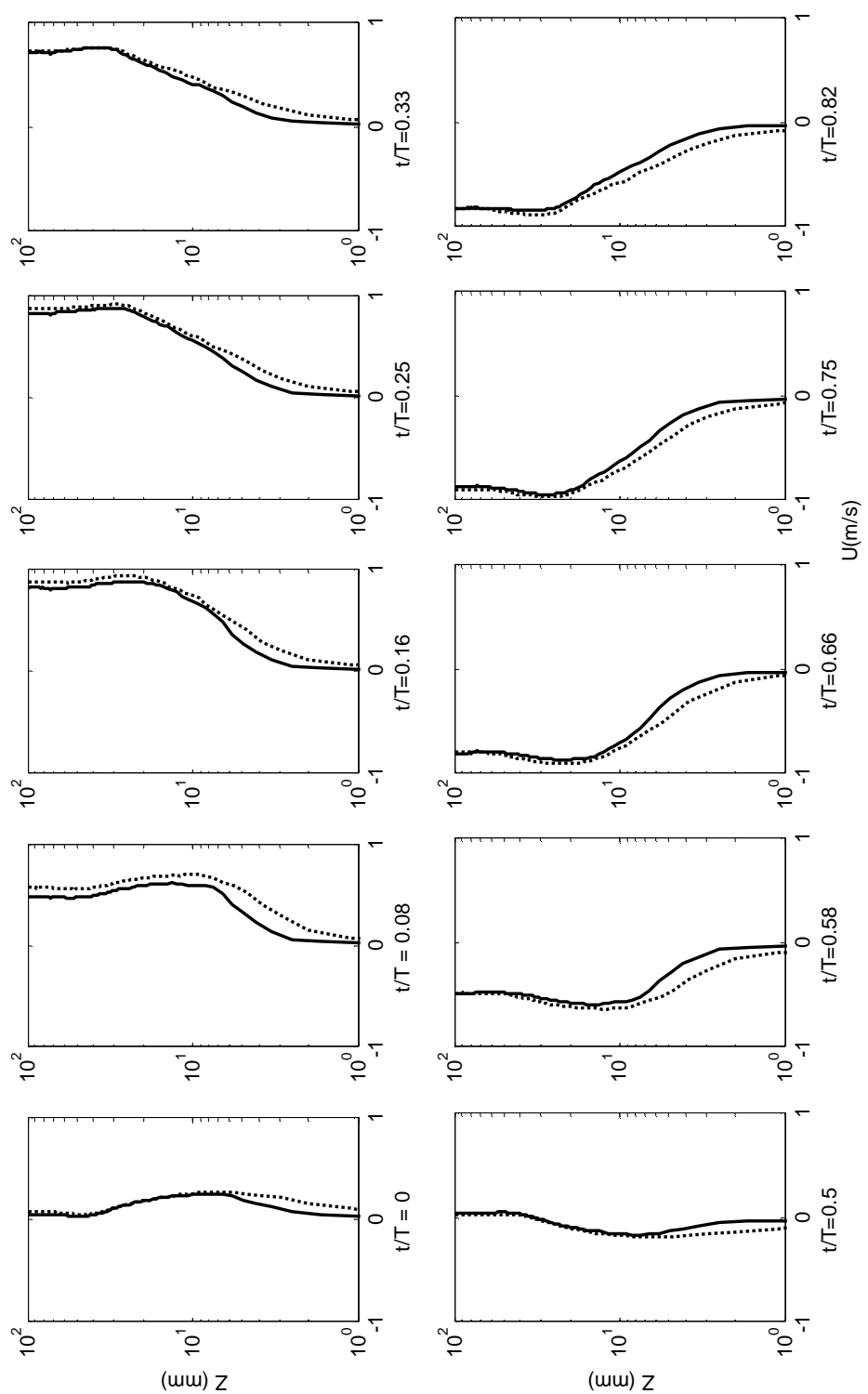


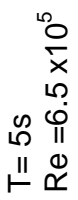
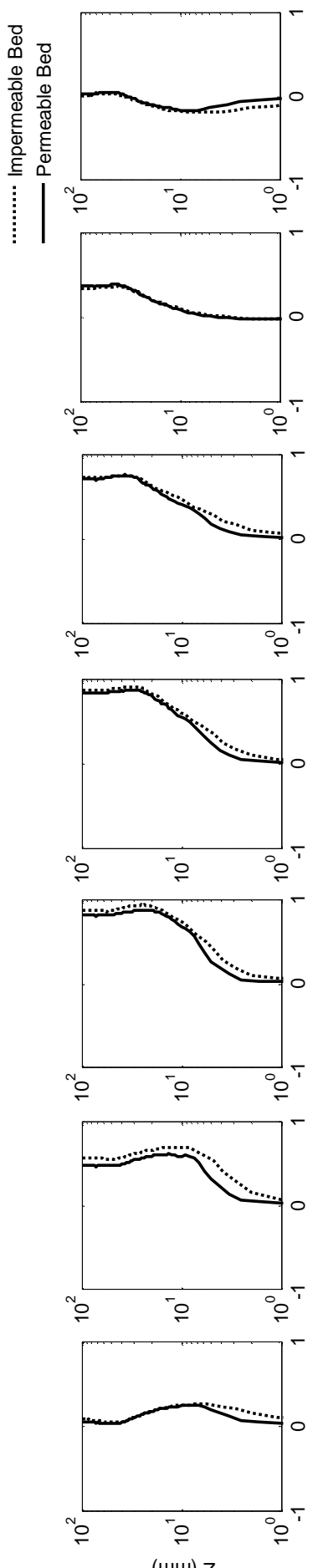

เอ」 \begin{tabular}{rl} 
& 0 \\
$\frac{0}{x}$ \\
0 \\
0 \\
0 \\
0 & 11 \\
11 & 0 \\
1 & \multicolumn{1}{|c}{}
\end{tabular}
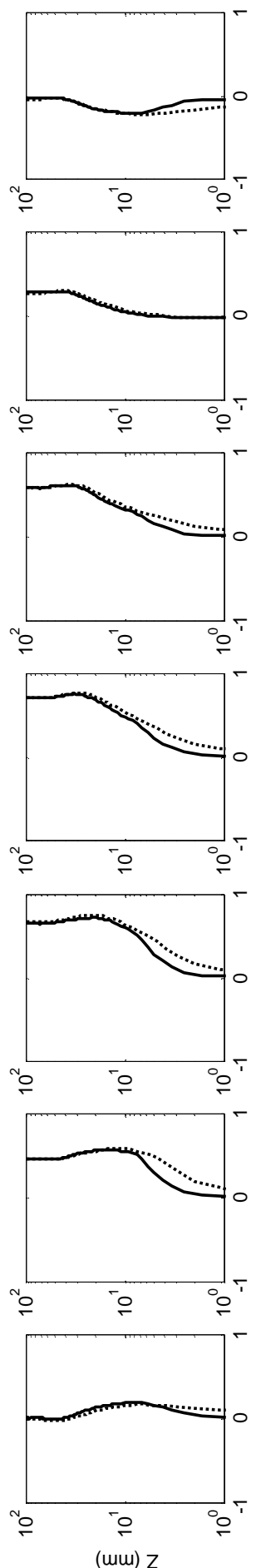

ट๐

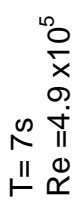
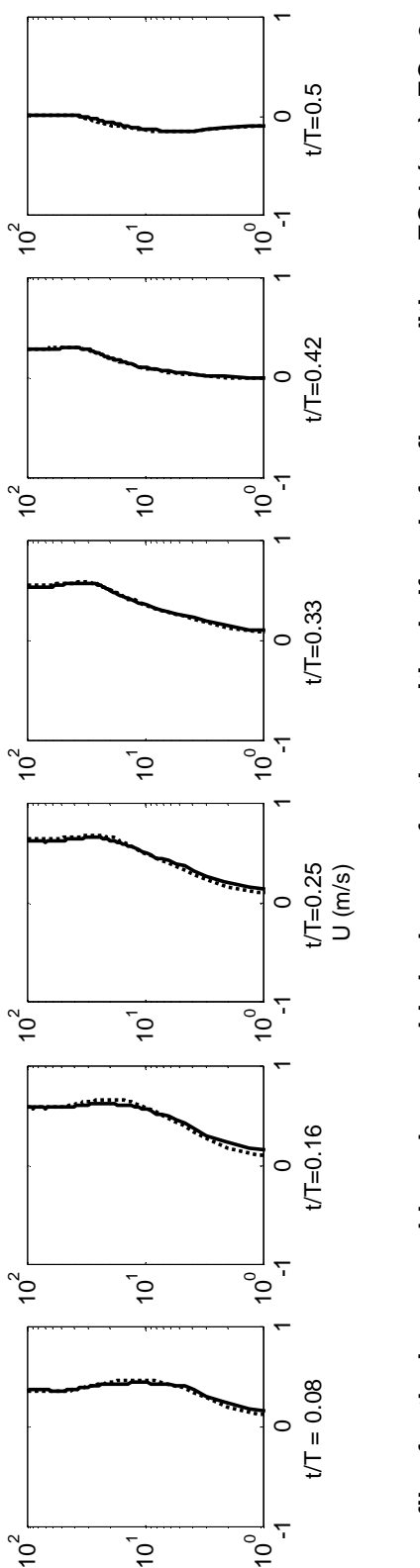

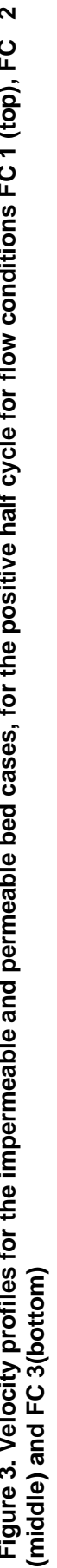

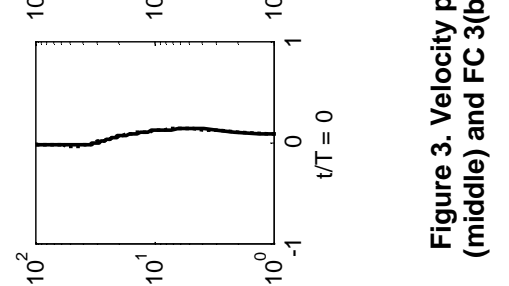

$\varepsilon \supset \dashv$ 
Fig. 3 demonstrates the velocity profiles for all three flow conditions, thus allowing the effect of bed permeability to be compared for various Reynolds numbers. Condition FC1 is shown at the top, this flow condition has the highest free-stream velocity, highest Reynolds number and the shortest period, FC3 is shown at the bottom, this has the lowest free-stream velocity, lowest Reynolds number and the greatest flow period. It can be seen that as the flow period increases and the Reynolds number decreases the difference between the impermeable and permeable velocity profiles becomes less pronounced. This suggests that the velocity difference between the impermeable bed and the permeable bed varies with Reynolds number and that for higher Reynolds numbers the inflection within the profile for the permeable bed is greater. This could be attributed to a higher level of turbulence and therefore an increase in the vertical exchange of the fluid. Alternatively, the separation of the flow over the individual grains could be occurring at an earlier point, creating a thicker form-induced sub-layer which could lead to the differences in the velocity profile. These points are still to be investigated in further detail.

\section{Phase lead}

The phase lead, $\phi$, for laminar flow over a smooth bed is $45^{\circ}$ near the bed and this is known to decrease with turbulence and the presence of a rough bed. The phase lead for our sinusoidal flow conditions is calculated as the phase difference between the phase of the free-stream maximum velocity, and the maximum velocity within the time series at the different elevations, this is shown in Fig. 4.

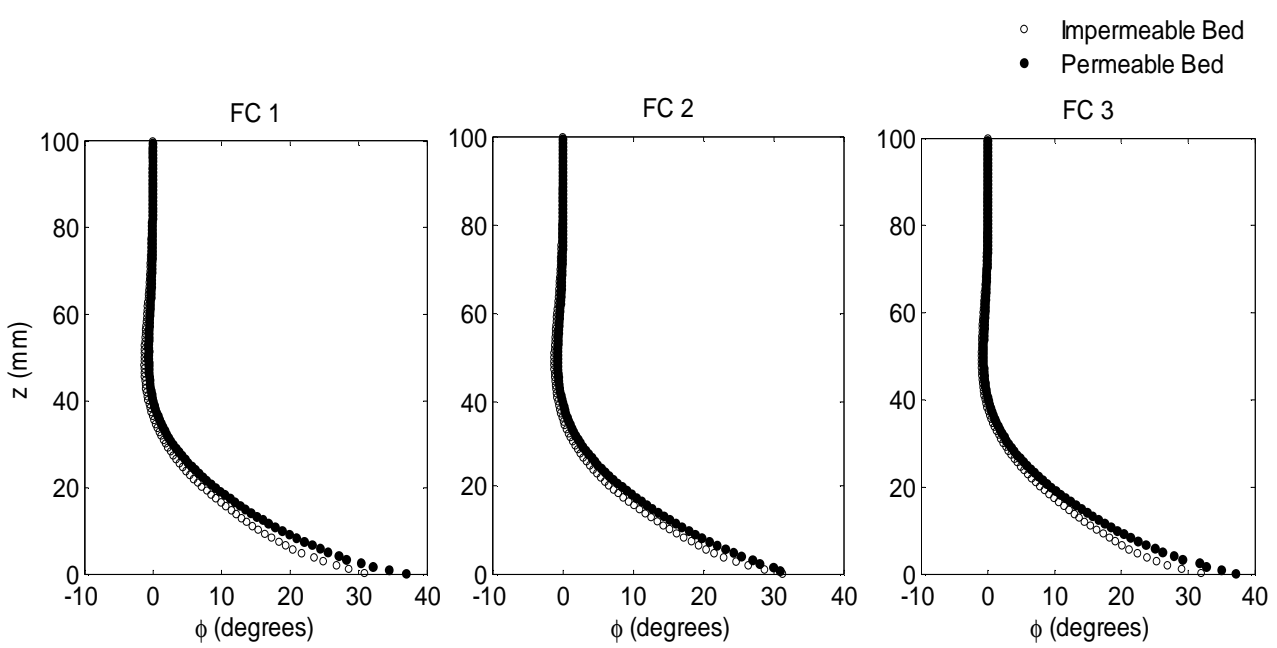

Figure 4: Phase lead against elevation above the bed $(z)$ for the impermeable and permeable bed. FC1(left), FC2(middle) and FC3(right).

The profiles in Fig. 4 show that in the lower $30 \mathrm{~mm}$ the phase lead for the permeable bed is constantly greater than the phase lead of the impermeable bed. This trend is consistent and applies to all flow conditions with the phase difference between the two cases is shown to be $5^{\circ}$ for the flow nearest the bed. This suggests that the near bed flow for the permeable bed is ahead of the impermeable bed, even though the free stream velocity over both beds is perfectly in phase. Therefore, time-dependent features of boundary layer flow, such as boundary layer thickness, bed shear stress and also the onset of turbulence could potentially occur ahead of the same features in the impermeable bed scenario. This $5^{\circ}$ phase lead can also lead to the noticeable differences in the impermeable and permeable bed velocity profiles that are illustrated in Fig. 2 and Fig. 3. This higher phase lead also indicates that the turbulence within the boundary layer and particularly near the bed is potentially lower for the permeable bed than for the impermeable bed. 


\section{Boundary layer thickness}

The boundary layer thickness, $\delta$, is defined in this study as the elevation from the bed at which the velocity defect, which is calculated as $u_{d}(z, t)=u_{0}(t)-u(z, t)$, is equal to $5 \%$ of $\mathrm{u}_{0 \max }$. A value of $5 \%$ has been chosen as opposed to the recommended $1 \%$ threshold to allow for experimental scatter within the results as adopted by Sleath (1987) and van der A et al. (2011). Defined this way the boundary layer thickness can be illustrated throughout the flow cycle as shown in Fig. 5 for both the permeable and impermeable beds for the three different flow conditions. It can be seen that the permeable bed has a slightly thicker boundary layer throughout the flow cycle, in particular at the start of the accelerating flow. The difference in boundary layer thickness throughout the cycle is approximately $3-6 \mathrm{~mm}$, this is about $0.33-0.67 d_{50}$. It can also be noted that the development of the boundary layer after flow reversal for the permeable bed occurs slightly ahead of the impermeable bed boundary layer, this supports the earlier discussion on the differences in phase lead for the two different bed cases.
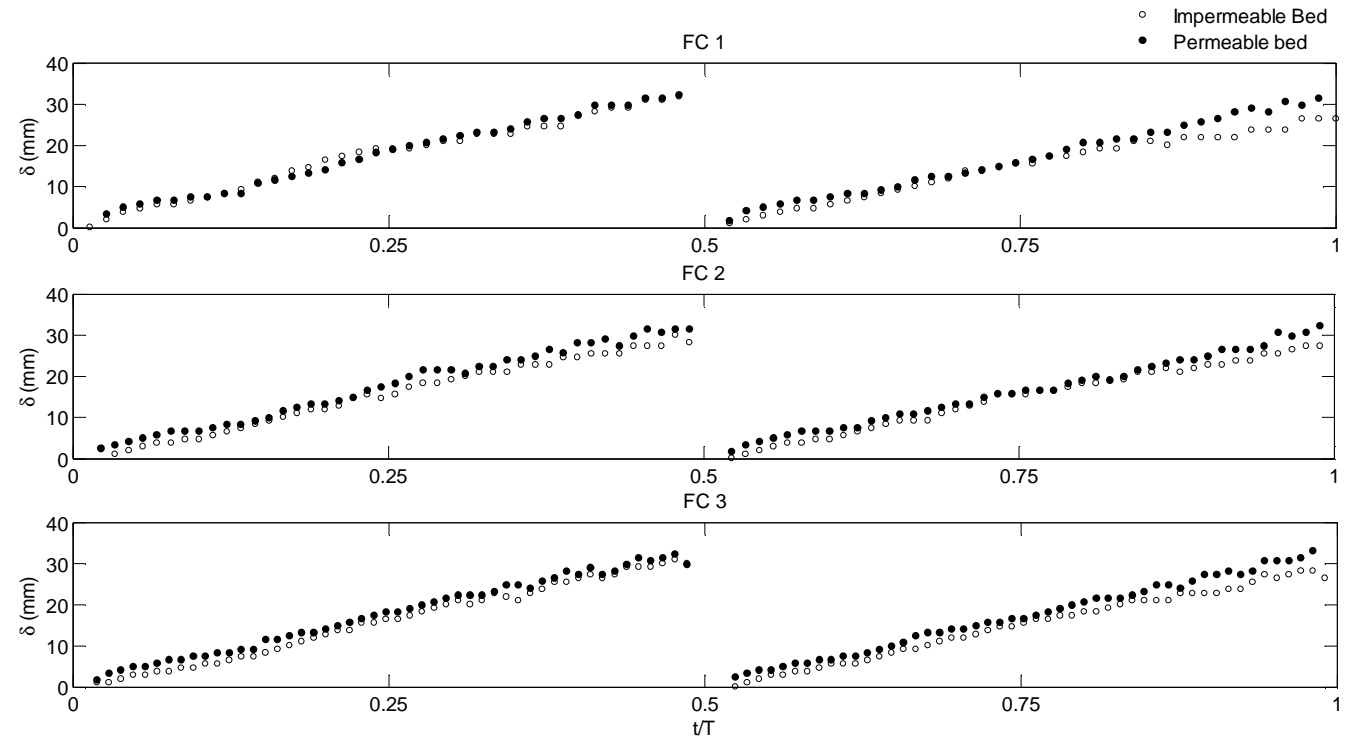

Figure 5: Boundary layer thickness throughout the flow cycle for the impermeable and permeable bed. FC1(top), FC2(middle) and FC3(bottom).

\section{Bed Shear stress}

The bed shear stress is one of the most important practical applications of this study as it is this that ultimately impacts erosion and sediment transport along with wave attenuation. Here the shear stress has been estimated using the log law in a similar manner to Sleath (1987), Jensen et al. (1989) and van der A et al. (2011) who all showed the existence of the logarithmic layer for large sections of the flow cycle. For rough wall boundary layers the log law can be expressed as:

$$
u=\frac{u_{*}}{\kappa} \ln \left(\frac{z+d^{\prime}}{z_{0}}\right)
$$

where $u_{*}$ is the friction velocity, $\kappa$ is von Karman constant, $\kappa=0.4, z$ is the bed-normal coordinate starting at the roughness crest, $d$ ' defines the position of the so-called zero-plane, i.e. zero-plane is located at distance $d^{\prime}$ ' below the roughness crest $\left(z=-d^{\prime}\right)$, and $z_{0}=k_{\mathrm{s}} / 30$ is the roughness length scale.

Eq.1 has been fitted to the instantaneous velocity profiles to estimate the shear velocity throughout the flow cycle. The zero plane offset, $d$ ', has been first calculated from the velocity 
profiles and averaged over the three flow conditions as $2.4 \mathrm{~mm}$ for the impermeable bed and $1.3 \mathrm{~mm}$ for the permeable bed. This means that for the permeable bed $d^{\prime}=0.14 d_{50}$ and for the impermeable bed $d^{\prime}=0.27 d_{50}$. These values were kept constant in the subsequent round of fitting. The log profile should be fitted to the region above the bed, away from the direct influence of the roughness elements and is contained within the constant stress layer. To allow for these conditions to be met the $\log$ profile has been fitted to the region where $z+d^{\prime}>0.2 k_{\mathrm{s}}$ and $z+d^{\prime}<$ (0.2-0.3) $\delta$ as per van der A et al. (2011). The fit has only been accepted when the correlation coefficient is greater than 0.95 and the fit is to more than 4 points. Fig. 6 shows the resulting shear velocity (top) and the resulting $k_{s}$ values (bottom) for both the impermeable bed and the permeable bed for the FC1 flow condition. The shear velocity is greater for the permeable bed than for the impermeable bed during the accelerating stages of the flow and similar for the decelerating stages, which corresponds to the earlier discussion. It can be seen that $k_{\mathrm{s}}$ values are approximately $2 d_{50}$ for both the permeable and impermeable cases.

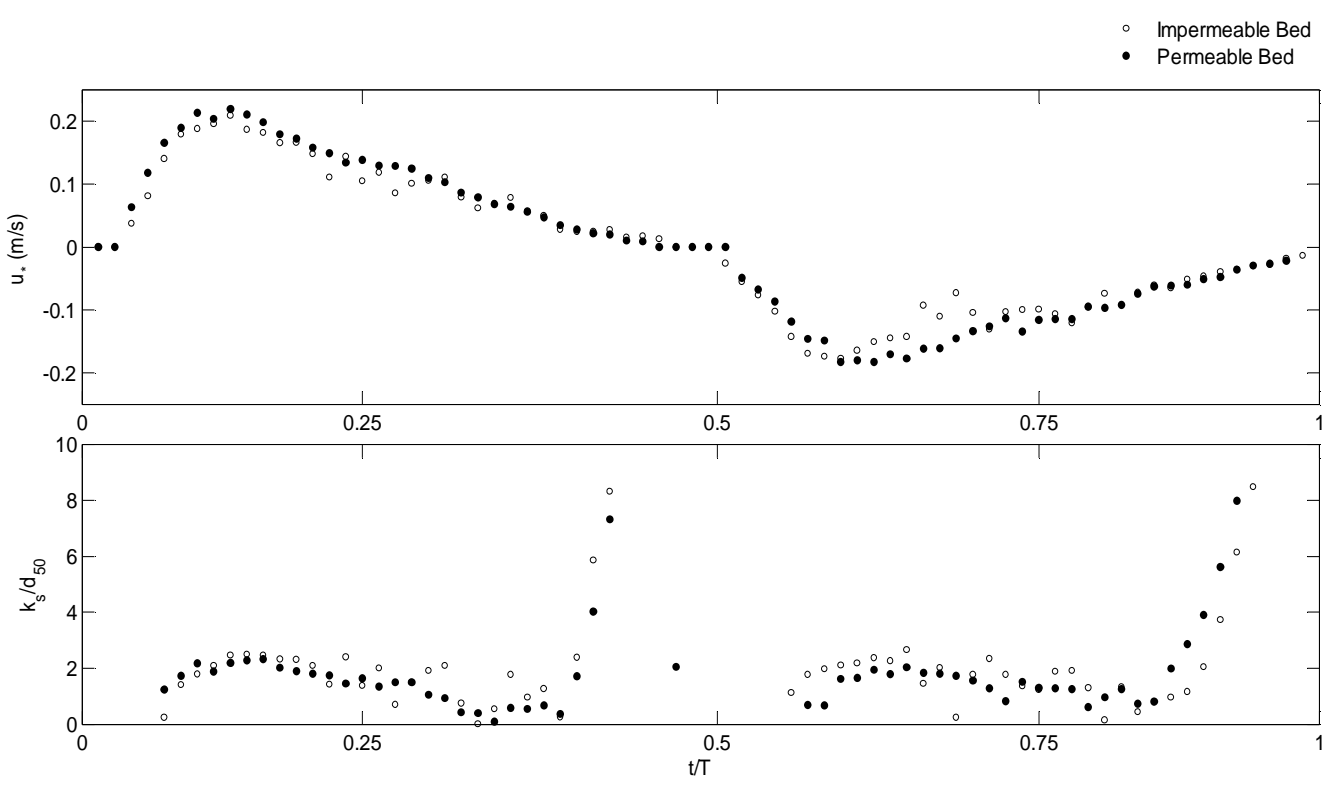

Figure 6: Top: Shear velocity throughout the flow cycle for FC2 for both the impermeable and permeable bed. Bottom: corresponding $\mathbf{k}_{\mathrm{s}}$ throughout the flow cycle.

The normalized bed shear stress, $\tau=\rho u_{*}^{2} / \rho U_{0}^{2}$, throughout the flow cycle is illustrated in Fig. 7 for the three different flow conditions. The top of the figures shows the flow condition FC1 with the highest free-stream velocity, the highest Reynolds number and the shortest flow period, and the flow condition that has the lowest velocity and Reynolds number but the longest flow period, FC3, is at the bottom.

It can be seen from Fig. 7 that during the accelerating parts of the flow the bed shear stress is greater for the permeable bed when compared to the impermeable bed, but that during the decelerating flow sections the two are very similar. This supports the differences in the velocity profiles seen before and can also be supported by the difference in phase lead, with the near bed velocities of the permeable bed being $5^{\circ}$ ahead of the impermeable bed, leading to an earlier development of bed shear stress. It is also interesting to note that this difference increases with increasing Reynolds number. The peak bed shear stress values for all the flow conditions are shown in Table 2. Here it can be seen that there is a distinct difference between the impermeable and permeable bed and that the difference is largest for flow FC1 which has the highest Reynolds number. For FC1 there is a $21 \%$ increase in the maximum shear stress for flows over the permeable bed when compared to flows over the impermeable bed, FC2 has a corresponding $9 \%$ 
increase and FC3 only has a 3\% increase. This can be attributed to the enhanced exchange of fluid providing a greater resistance to the horizontal velocity near the bed as was seen in the velocity profiles. Essentially, with increasing Reynolds number, the exchange of fluid between the boundary layer and the porous bed increases, therefore providing a higher resistance to the horizontal flow which causes a steeper velocity gradient and results in larger bed shear stress.
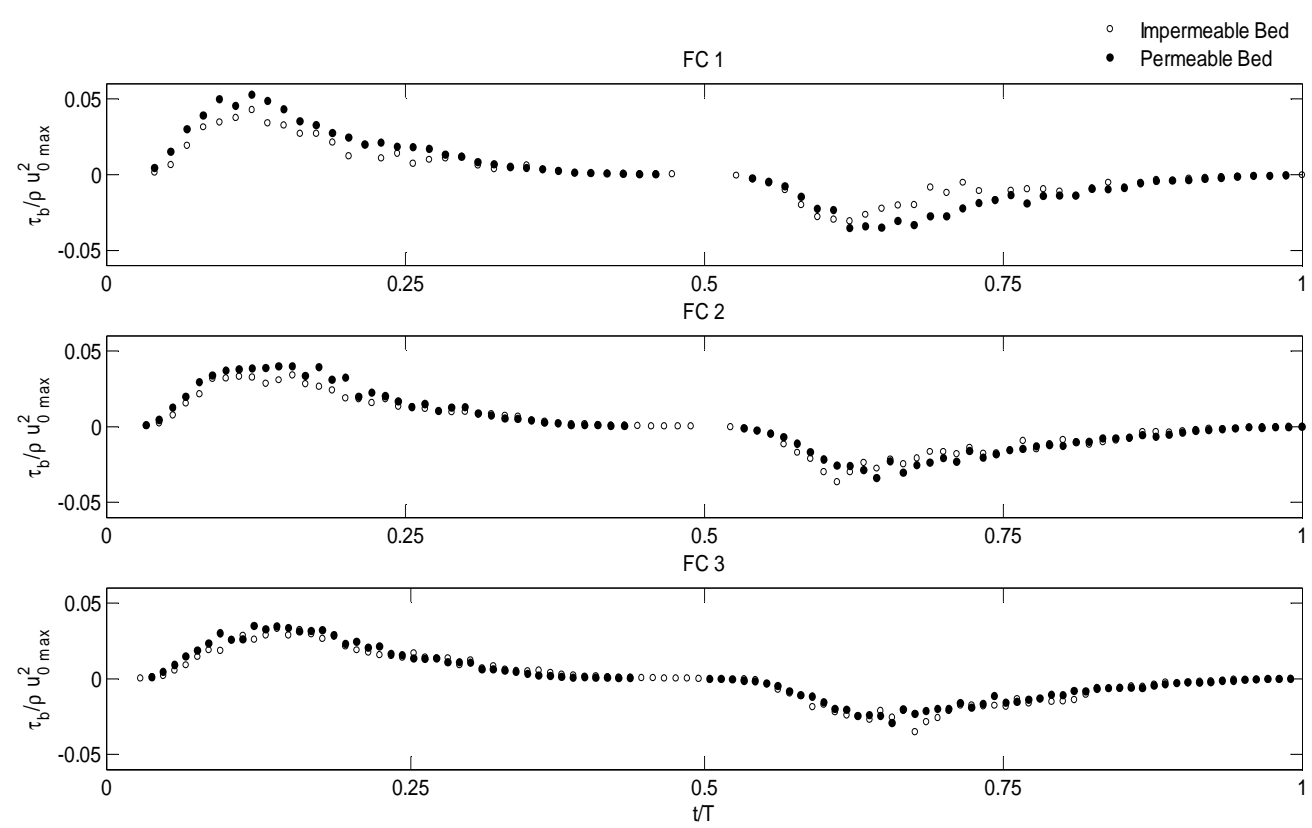

Figure 7: Bed shear stress from log law fitting throughout the flow cycle for both the impermeable and permeable bed. FC1 (top), FC2 (middle) and FC3 (bottom).

\begin{tabular}{|c|c|c|}
\hline \multicolumn{2}{|c|}{ Table 2: Maximum Bed Shear Stress } \\
\hline \multirow{2}{*}{ Flow ID } & \multicolumn{2}{|c|}{ Shear Stress $\left(\mathrm{N} / \mathrm{m}^{2}\right)$} \\
\cline { 2 - 3 } & Impermeable bed & Permeable Bed \\
\hline FC1 & 37.2 & 45.2 \\
FC2 & 23.3 & 25.4 \\
FC3 & 16.9 & 16.2 \\
\hline
\end{tabular}

\section{Friction factor}

The bed friction factor is important because it is a measure of the magnitude of stresses that are brought about because of the presence of the bed on the flow. The friction factor can be calculated from the measured maximum bed shear and free-stream velocity as follows

$$
f_{w}=\frac{2 \tau_{\mathrm{b}, \max }}{\rho u_{0 \max }^{2}}
$$

Fig. 8 displays the friction factor for the three flow conditions for both the impermeable bed and the permeable bed. It can be seen that the friction factors for the impermeable bed tend to a constant when the flow is in the rough turbulent regime. For the same flow conditions the friction factor for the permeable bed is higher for FC1 and FC2. Here the fiction factor is greater by $11 \%$ for $\mathrm{FC} 2$ and $36 \%$ for $\mathrm{FC} 1$ for the permeable bed case when compared to the equivalent 
impermeable bed. This means that for the permeable bed the friction factor increases with increasing Reynolds number in the range of Reynolds numbers where, based on the impermeable bed results, it would have been expected to be constant. This is a similar phenomenon that was noted during the uni-directional flow investigations of Zagni and Smith (1976), Zippe and Graf (1983) and Manes et al. (2011). Manes et al. (2011) suggested that the increase in friction factor is due to the increase of momentum penetration within the permeable bed with increasing Reynolds number.

This finding however goes against the current understanding of friction factors under oscillatory flow conditions as suggested by Jonsson (1966), Swart (1974), Kamphuis (1975), and Nielsen (1992) whose formulae are widely used in coastal engineering practice. It seems that these formulas are therefore not applicable to highly turbulent flows over permeable beds such as cobbles, gravels and coarse sands. However, given the limited range of the experiments in terms of bed material and also flow conditions, the full extent of this phenomenon is not yet known.

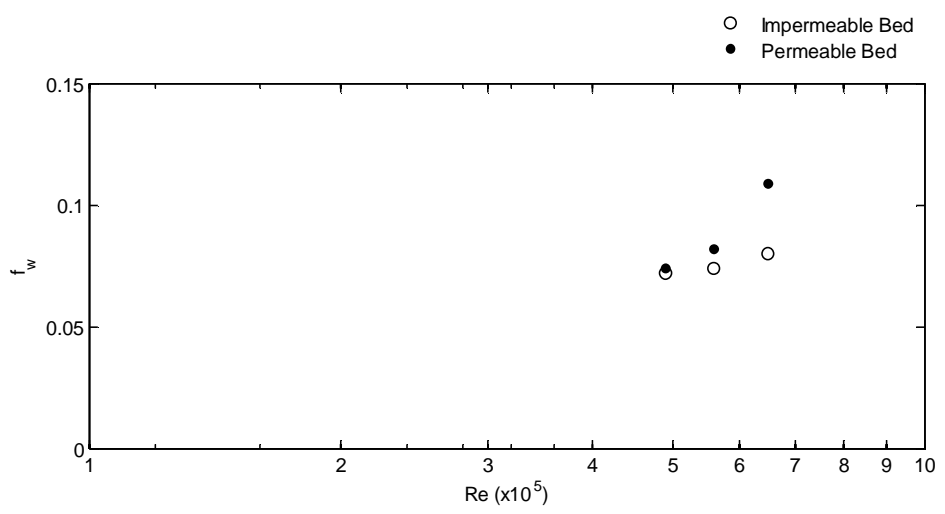

Figure 8: Maximum friction factor against Reynolds number for the impermeable and permeable bed.

\section{CONCLUSION}

A new experimental study is presented involving full-scale oscillatory boundary layer flow over permeable and impermeable rough beds. High resolution velocity measurements were obtained using PIV for a variety of flow conditions. The following conclusions are drawn from the study:

- $\quad$ The velocity profile for flow over a permeable bed is significantly different than velocity profile over the impermeable bed with identical surface roughness. For the permeable bed, the profile exhibits an inflection point at the bed surface and lower near-bed velocities.

- Near-bed flows over the permeable bed have up to a $5^{\circ}$ larger phase lead, and develop a marginally thicker boundary layer throughout the cycle, compared to equivalent flows over the impermeable bed.

- For the range of flow conditions investigated in this study the shear stresses and friction factors were up to $36 \%$ higher for flows over the permeable bed. For Reynolds numbers higher than those investigated in this study the effect of permeability is likely to increase.

- Friction factors for flows over a permeable exhibit a dependence on the flow Reynolds number and so subsequently increase with increasing Reynolds number. This differs significantly from the friction factor behavior for the same flows over an impermeable bed, where the friction factor remains constant with increasing Reynolds number. 
These findings have direct implications for the engineering models used to predict coastal erosion and sediment transport on steep gravel beaches, or for wave attenuation over permeable breakwaters.

\section{ACKNOWLEDGEMENTS}

The authors would like to acknowledge the University of Aberdeen's Fluid laboratory technicians Grant Cordiner and Roy Gillanders for their help in setting up the experiments.

\section{REFERENCES}

Breugem, W. P., B. J Boersma, and R. E. Uittenbogaard. 2006. The influence of wall permeability on turbulent channel flow, J. Fluid Mech., 562, 35-72.

Conley, D. C. and D. L. Inman. 1994. Ventilated oscillatory boundary layers, J. Fluid Mech., $273,261-284$.

Finnigan, J. J. 2000. Turbulence in plant canopies. Annu. Rev. Fluid. Mech., 32, 519-571

Jensen, B. M., B. M. Sumer. and J. Fredsøe. 1989. Turbulent oscillatory boundary layers at high Reynolds number. J. Fluid Mech., 206, 265-297.

Jonsson, I. G. 1966. Wave boundary layers and friction factors, Proceedings of $10^{\text {th }}$ International Conference on Coastal Engineering. ASCE, 127-148

Jonsson, I. G. and N. A. Carlsen. 1976. Experimental and theoretical investigations in an oscillatory turbulent boundary layer. J. Hydraul Res., 14, 45-60

Kamphuis, J, W. 1975. Friction factor under oscillatory waves, J. Waterw, Port, Coastal and Ocean Eng. Div 101(WW2), 135-144.

Kong, F. Y. and J. A. Schetz. 1982. Turbulent boundary layer over porous surfaces with different surface geometries, AIAA paper, 82-0030.

Manes, C., D. Pokrajac, V. I. Nikora, L. Ridolfi and D. Poggi. 2011. Turbulent friction in flows over permeable walls, Geophys. Res. Lett., 38. L034002.

Nielsen, P. 1992. Coastal Bottom Boundary Layers and Sediment Transport, World Scientific.

Raupach, M. R., J. J. Finnigan and Y. Brunet. 1996. Coherent eddies and turbulence in vegetation canopies: the mixing-layer analogy. Boundary-Layer Meteorology, 78, 351-382

Sleath, J. F. A. 1987. Turbulent oscillatory flow over rough beds. J. Fluid Mech., 42, 111-123.

Steenhauer, K. 2010. An experimental and numerical study of surface-subsurface interaction for bore-driven swash on a coarse-grained beach, $\mathrm{PhD}$ thesis. University of Aberdeen.

Swart, D. H. 1974. Offshore sediment transport and equilibrium beach profiles. In Publication No. 131 Delft Hydraulics Laboratory

van der A, D. A. 2010. Effects of Acceleration Skewness on Oscillatory Boundary Layers and Sheet Flow Sand Transport. PhD Thesis. University of Aberdeen.

van der A, D. A., T. O’Donoghue, A. G. Davies, and J. S. Ribberink. 2011. Experimental study of the turbulent boundary layer in acceleration-skewed oscillatory flow, J. Fluid Mech., 684,251-283.

Zagni, A. F. E., and K. V. H. Smith. 1976. Channel flow over permeable beds of graded spheres, J. Hydraul. Div., 102, 207-222.

Zippe, H. J., and W. H. Graf. 1983. Turbulent boundary-layer flow over permeable and nonpermeable rough surfaces, J. Hydraul. Res., 21(1), 51-65. 